Original Research

\title{
The Necessity of Ergonomic Considerations in Accreditation of Hospitals with Emphasize on Elderly Features
}

\author{
Mahboubeh Sadat Rahmanpour ${ }^{1}$, Abbas Ebadi $^{2}$, Aram Tirgar $^{3 *}$
}

1. MSc Student of Health of Elderly, Student Research Center Committee, Babol University of Medical Sciences, Babol, Iran

2. Behavioral Sciences Research Center, Baqiyatallah University of Medical Sciences, Tehran, Iran

3. Social Determinant of Health Research Center, Health Research Institute, Babol University of Medical Sciences, Babol, Iran

\begin{tabular}{ll}
\hline \multicolumn{2}{c}{ Article Info } \\
\hline Original Article \\
Received: & $2018 / 09 / 17$ \\
Accepted: & $2018 / 11 / 24$ \\
Published Online: & $2018 / 12 / 25$
\end{tabular}

DOI: 10.30699/jergon.6.3.1

Use your device to scan and read the article online

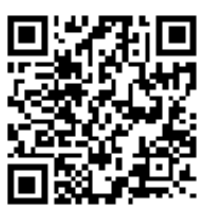

Corresponding Information

\section{Aram Tirgar,}

Social Determinant of Health Research Center, Health Research Institute, Babol University of Medical Sciences, Babol, Iran

Email:

a.tirgar@mubabol.ac.ir

\begin{abstract}
Background and Objectives: The objective of hospital accreditation is to increase the safety and satisfaction of patients and employees, with the contribution of which can be achieved through environmental adaption. The present study aimed to explain the necessity of using ergonomic considerations in the process of hospital accreditation.
\end{abstract}

Methods: This methodological study was designed in 2018 and simultaneously conducted with the psychometric evaluation and validation of the structural fitness assessment tool of age-friendly hospitals. The determination of the structural components was done by examining the texts and validating the items using the Delphi method. After determining the content validity, classification of items into mandatory or essential sections was made by obtaining at least two thirds and one thirds of the experts votes, respectively. Descriptive and inferential statistics were used for data processing.

Results: The processing of expert opinion about 72 items (content validity) showed that the majority of subjects (55 items equivalent to $76 \%$ ) were mandatory or essential, with the highest proportion of mandatory cases being made by the gerontologists, and the least architectural experts.

Conclusion: Considering the growth of the elderly population in the country and, on the other hand, the high contribution of the elderly to the treatment centers, and the necessity or basicity of the majority of tool items, the application of ergonomic principles in the accreditations seems necessary.

Keywords: Ergonomics, Accreditation, Elderly, Hospital, Tools

Copyright (C) 2018, Journal of Ergonomics. This is an open-access article distributed under the terms of the Creative Commons Attribution-noncommercial 4.0 International License which permits copy and redistribute the material just in noncommercial usages, provided the original work is properly cited

How to Cite This Article:

Rahmanpour M S, Ebadi A, Tirgar A. The Necessity of Ergonomic Considerations in Accreditation of Hospitals with Emphasize on Elderly Features. J Ergon. 2018; 6 (3):1-10 


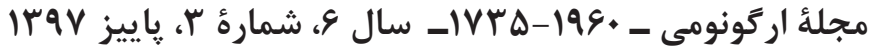

مقاله يزوهشى

ضرورت ملاحظات اركونوميك در اعتباربخشى به بيمارستان ها با تأكيد

\author{
بر ويثز هاى هالى سالمندان

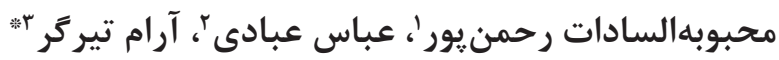

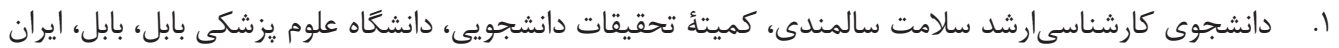

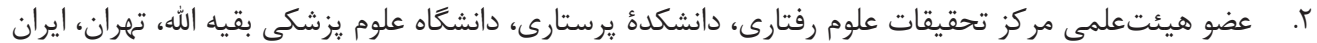

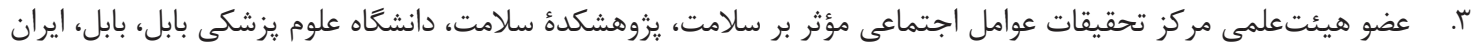

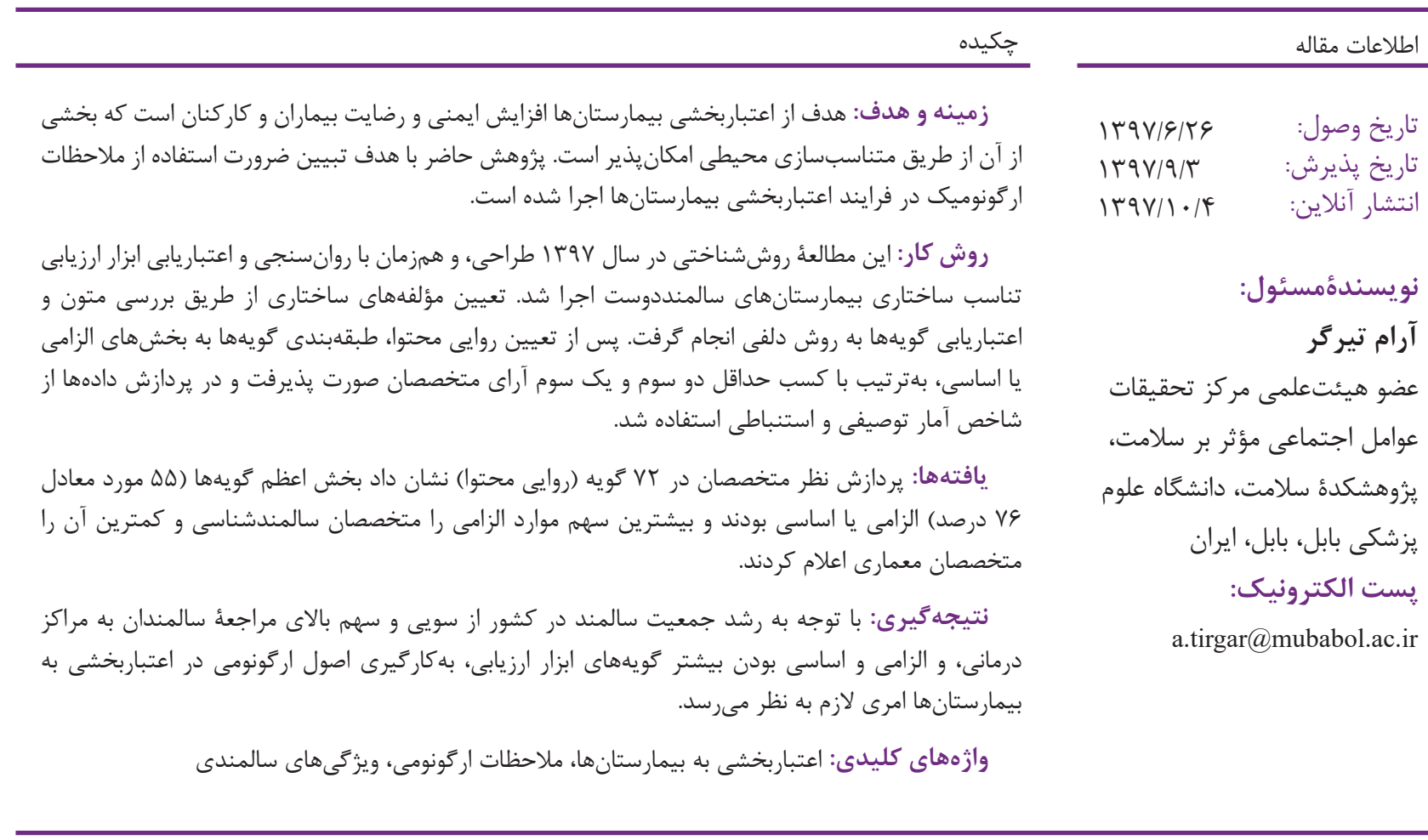

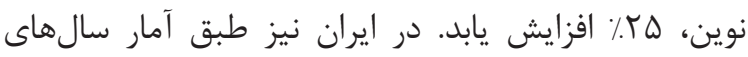

مقدمه

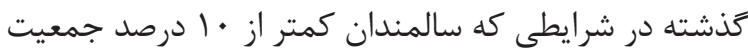

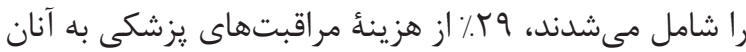

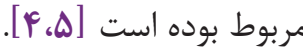

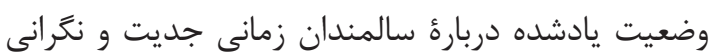

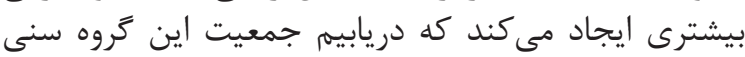

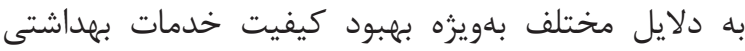

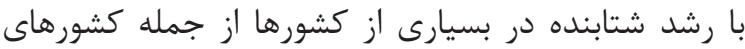

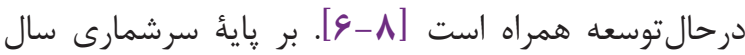

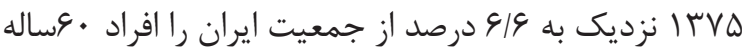

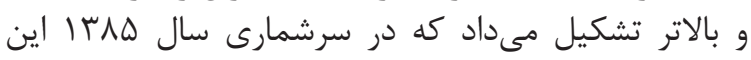

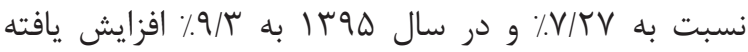

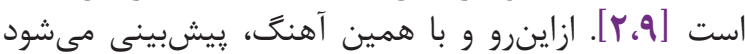

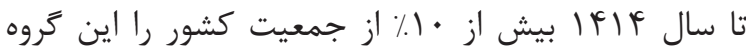

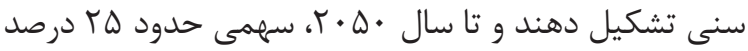

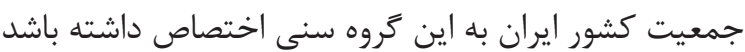

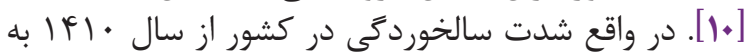

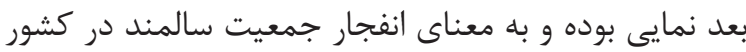

كر جه سالمندان در بسيارى از كشورها طبقة ارشد جامعهد

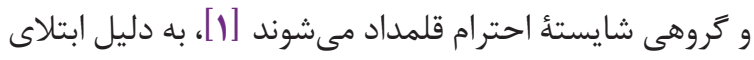

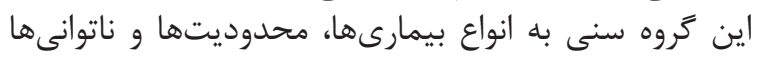

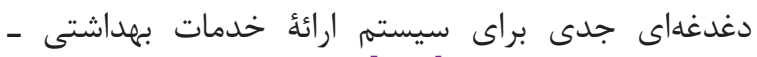

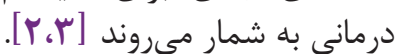

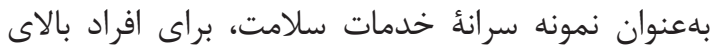

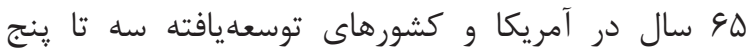

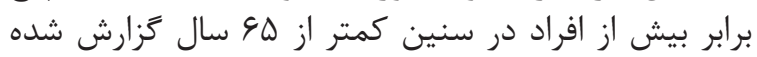

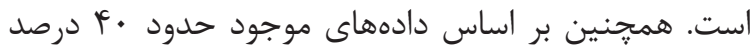

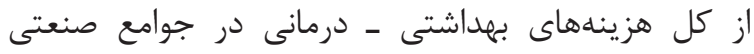

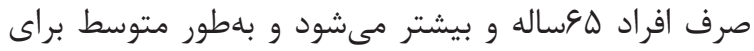

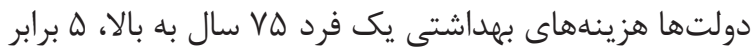

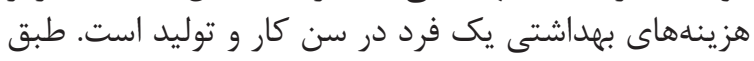

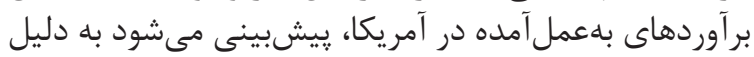

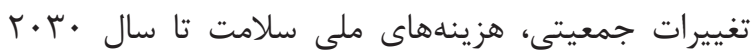

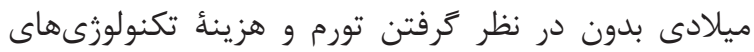




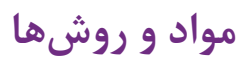

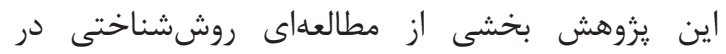

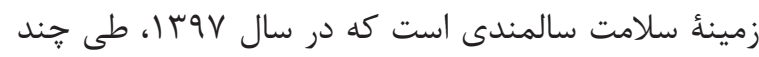

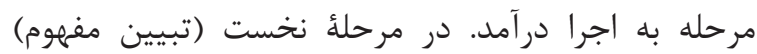

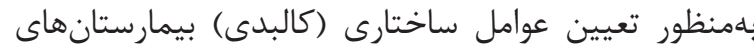

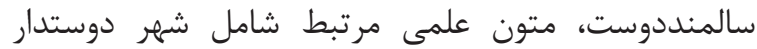

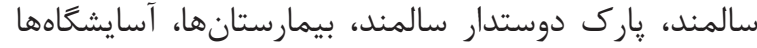

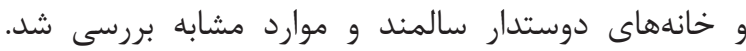

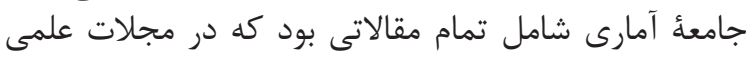

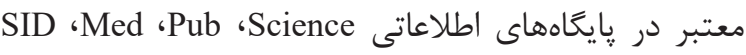
Iran Medex و direct

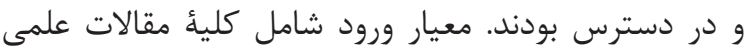

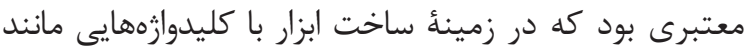
Tool, Instrument, Test, Index, Questionnaire, Inventory, Scale, Checklist متناسبسازى محيطهاى فيزيكى مانند بيمارستان، مركز

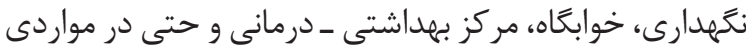

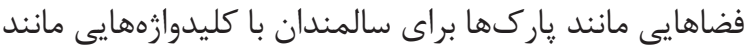

.Age friendly, Senior friendly, Elderly friendly

در مرحله دوم (توليد گويه) يس از شناسايى مؤلفهها،

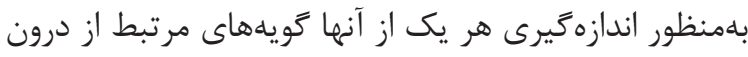

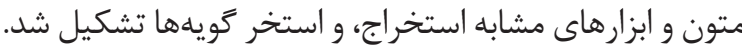
در مرحلة سوم (اعتباريابى) تعيين روايى محتوا انجام

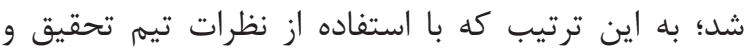

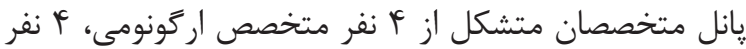

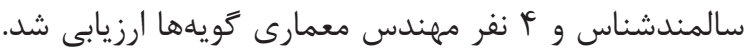

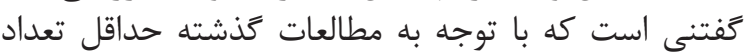

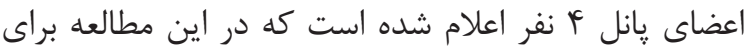

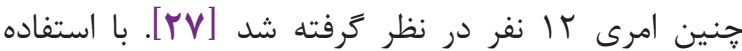

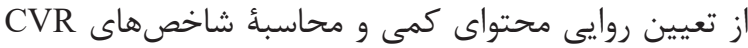

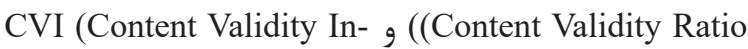
dex )، ₹ويdهاى نامناسب حذف شدند. براى محاسبة CVR از متخصصان درخواست شد ضرورت وجود هر گويه را در رابطه با تناسب ساختارى بيمارستان

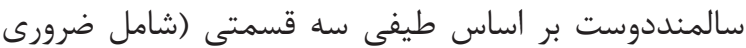

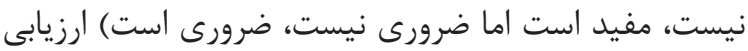

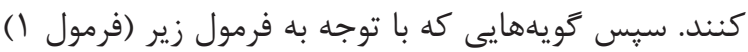

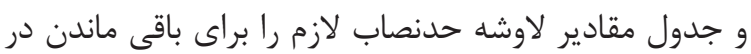

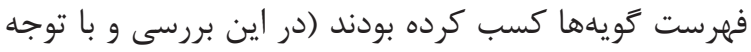

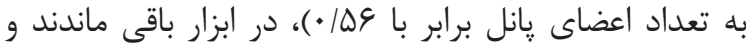
ديخر زويه حذف شدند.
است [r/،11].

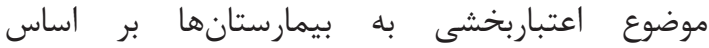

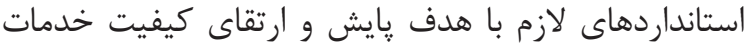

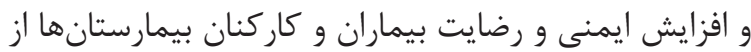

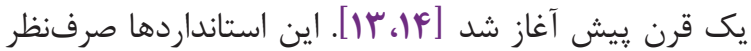

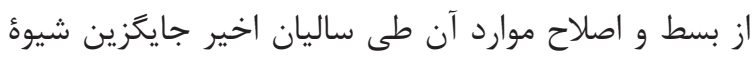

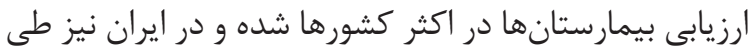

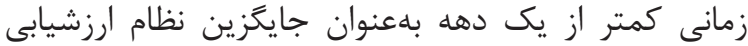

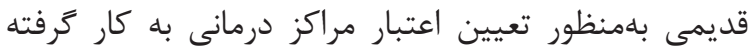

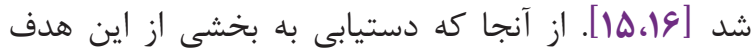

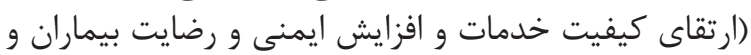

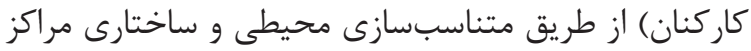

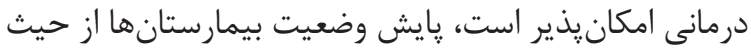

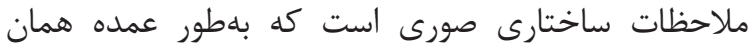

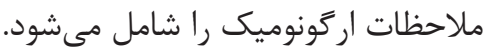
بررسىها نشان داده است ابزارهاى مختلفى براى ارزيابى

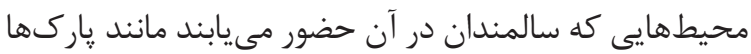

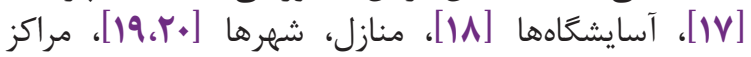

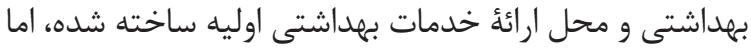

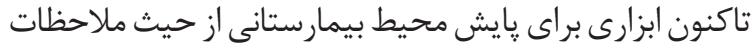

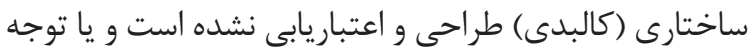

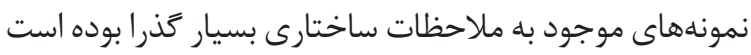

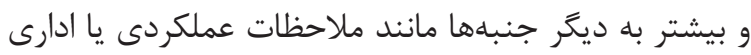

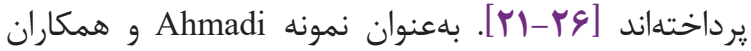

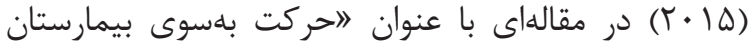

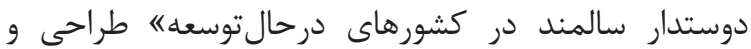

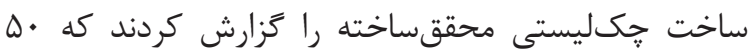

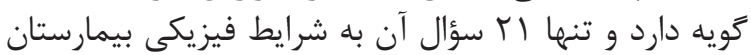

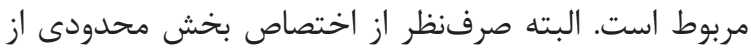

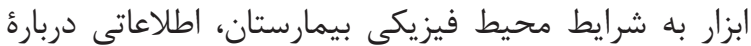

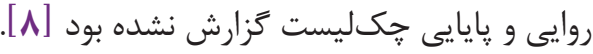
ازئار آنجا كه همسويى و هميوشانى نزديكى بين اهداف

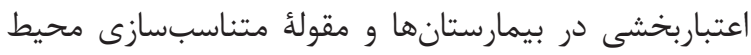

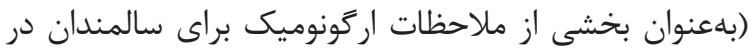

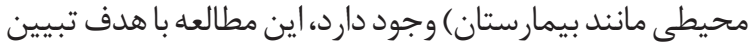

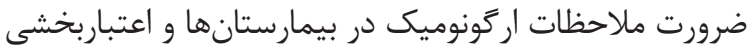

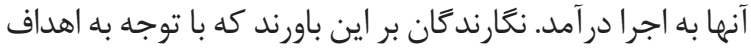

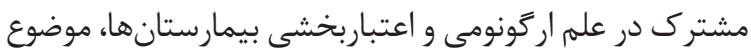

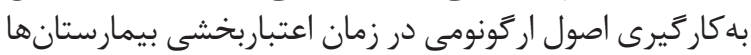

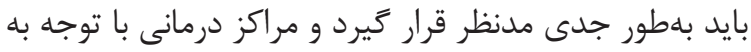
ميزان رعايت اين اصول رتبهابندى شوند مدرئ

تعداد كل متخصصان

$\mathrm{CVR}=$

تعدان كل منخصصان - تعداد متخصصانى كه عزينهُ ضرورى را انتخاب كردهاند

تعداد كل متخصصان 


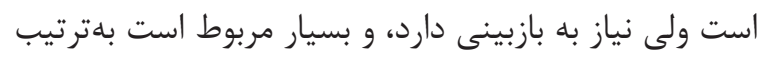

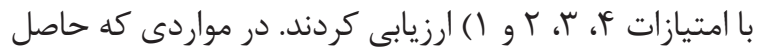

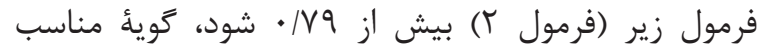
تشخيص داده شده و در ابزار باقى خواهد ماند
در ادامٔ محاسبه، CVI و تعيين ارتباط كويهها با موضوع

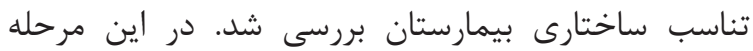

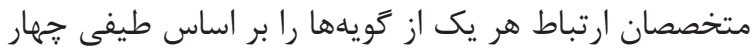

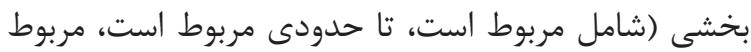

$$
\text { CVI= تعداد متخصصانى كه به كويه نمره ب و Fٔ دادهاند مت متخصصان }
$$

دارد بهترينها را براى سالمندان بيمار فراهم سازد.

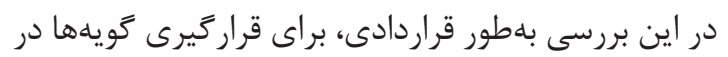

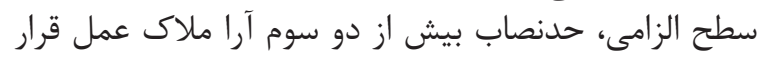

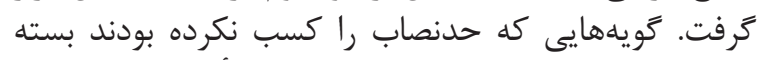

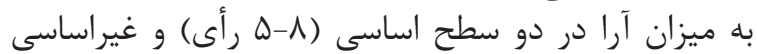

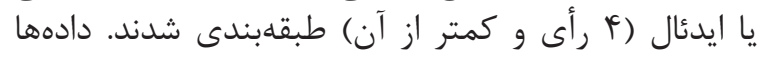

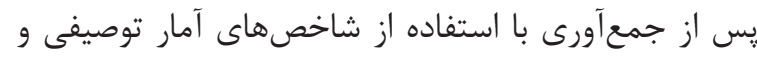

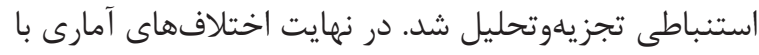

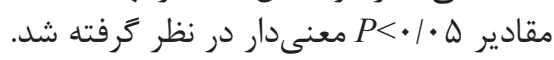

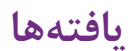

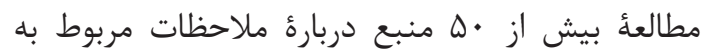

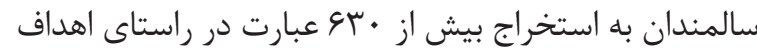

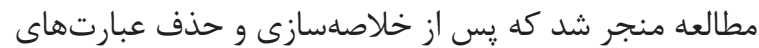

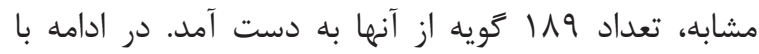

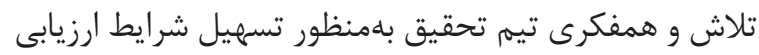

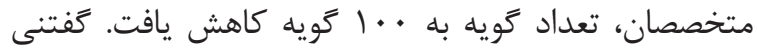

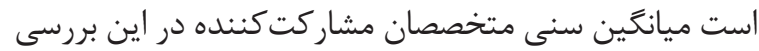

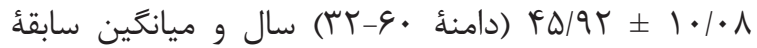
كارى آنها 9/AF

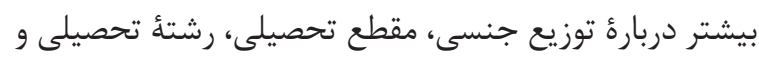

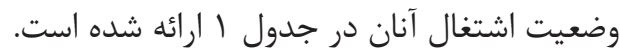

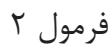

بهمنظور ارزش كذارى و سطحبندى كويهها نيز مانند

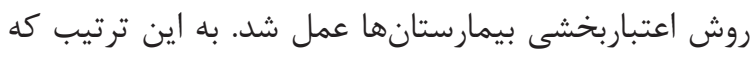

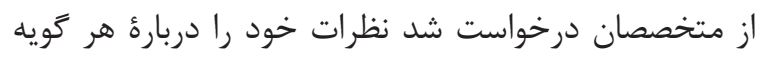

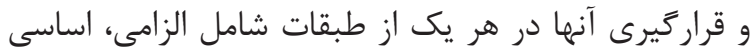

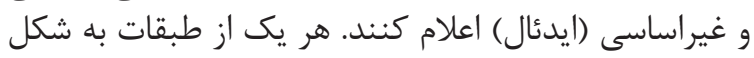

$$
\text { زير تعريف و تعيين شد. }
$$

موارد الزامى به مواردى اطلاق مىشود كه تمام

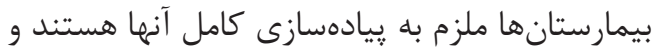

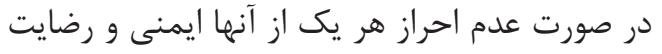

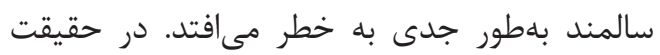

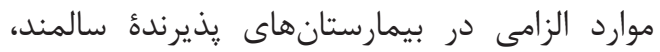

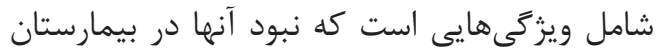

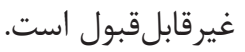

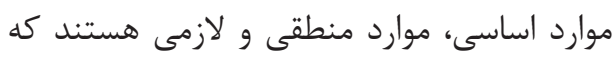

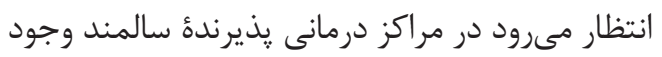

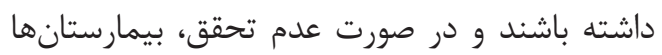

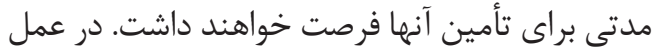

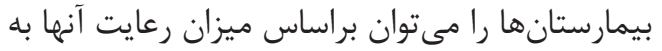

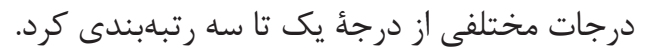

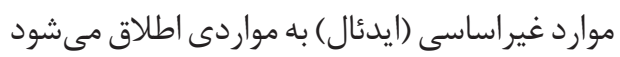

\begin{tabular}{|c|c|c|c|}
\hline فراوانى نسبى (٪) & فراوانى & سطح & متغير \\
\hline$V \Delta$ & 9 & مرد & \multirow{2}{*}{ جنس } \\
\hline Ta & r & زن & \\
\hline FI/99 & $\Delta$ & دكتراى تخصصى & \multirow{2}{*}{ مقطع تحصيلى } \\
\hline & v & كارشناسىارشد & \\
\hline سז/r & f & سالمندشناسى & \multirow{3}{*}{ تخصص } \\
\hline אسוץ & f & ارخونومى & \\
\hline שr/זr & f & معمارى & \\
\hline 99199 & $\wedge$ & عضو هيئت علمى & \multirow{2}{*}{ وضعيت اشتغال } \\
\hline אץ/سז & r & غير هيئت علمى & \\
\hline
\end{tabular}

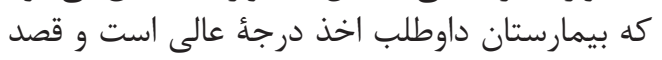

جدول ا. اطلاعات جمعيتشناختى متخصصان مشاركتكننده در ارزيابى تناسب ساختارى بيمارستان هاى سالمنددوست $($ Ir=n) 
داد بخش اعظم گويهها (ها مورد معادل V9 درصد) به نظر

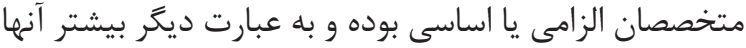

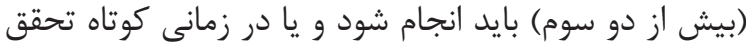

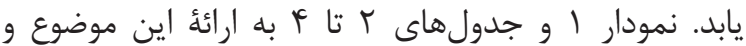
اطلاعات بيشتر اختصاص يافته است.
يردازش نظرات متخصصان و محاسبة شاخصهاى نVR

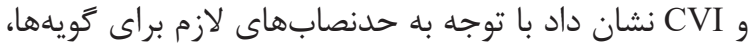

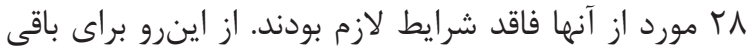

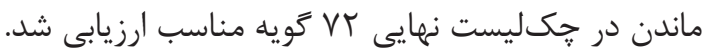

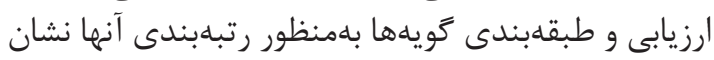

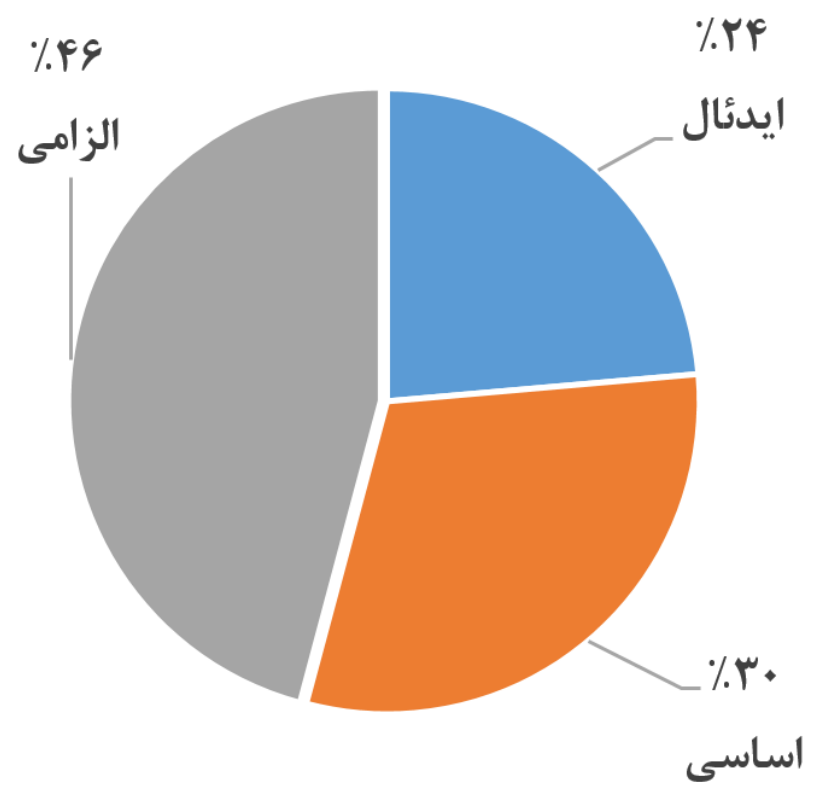

شكل ا. نسبت توصيههاى الزامى، اساسى و ايدئال در ابزار ارزيابى بيمارستانهاى دوستدار سالمند به تشخيص متخصصان اركونومى، سالمندشناسى و معمارى ارئي

جدول r. فهرست كَويههاى الزامى در ابزار ارزيابى بيمارستانهاى دوستدار سالمند

\begin{tabular}{|c|c|c|c|}
\hline موافقت & موافقت & \multirow{2}{*}{ كويه } & \\
\hline \multicolumn{2}{|c|}{ الزامى } & & ساختارى \\
\hline $1 \cdots$ & it & سطوح براى حركت سالمندان، صندلى خرخدار يا واكر كاملاً هموار است. & \multirow{3}{*}{ محيط بِيرامون } \\
\hline N & 1 . & علائم لازم بهمنظور معرفى مكانها و هدايت سالمندان نصب شده است. & \\
\hline VQ & 9 & مسيرهاى حركت از مصالح مقاوم و غيرلغزنده ساخته شده است. & \\
\hline$\Lambda$ & $1 \cdot$ & واحد يذيرش نزديك به در ورودى و بهراحتى قابلتشخيص است. & \multirow{2}{*}{ 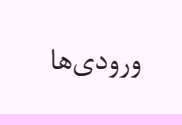 } \\
\hline VD & 9 & ورودى شيشهاى با ضربدر رنكى مشخص شده است. & \\
\hline $1 \cdots$ & ir & 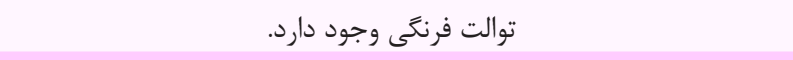 & \multirow{10}{*}{ سرويس بهداشتى } \\
\hline $1 \cdots$ & it & وسايل الكتريكى حمام به سيستم اتصال به زمين مجهز است. & \\
\hline 94 & 11 & بامنظور كمك به سالمندان براى برخاستن ميلههايى در توالت وجود دارد. & \\
\hline זی & 1. & ميلههايى در كنار وان يا دوش براى برخواستن يا حفظ تعادل وجود دارد. & \\
\hline VD & 9 & سرويسهاى بهداشتى كافى است. & \\
\hline VQ & 9 & توالت فضاى كافى براى خرخش صندلى خرخدار و حضور همراه دارد. & \\
\hline VD & 9 & حمام فضاى كافى براى خرخش صندلى خرخدار و حضور همراه دارد. & \\
\hline VD & 9 & حمام سيستم زنت هشدار دارد. & \\
\hline sV & $* 1$ & روشويى ارتفاعى دارد كه صندلى خرخدار مىتواند زير آن قرار بحيرد. & \\
\hline $9 V$ & $* \wedge$ & درب توالت به سمت بيرون باز مىشود يا كشويى است. & \\
\hline
\end{tabular}




\begin{tabular}{|c|c|c|c|}
\hline موافقت & موافقت & \multirow[t]{2}{*}{ كويه } & 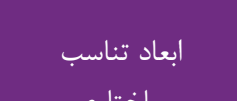 \\
\hline \multicolumn{2}{|c|}{ الزامى } & & ساختارى \\
\hline$\Lambda$ & $1 \cdot$ & صندلى بدون جرخ است و جهار يائُ محكم و مستقل دارد. & \multirow{3}{*}{ مبلمان بيمارستان } \\
\hline Va & 9 & صندلىها و نيمكتها دستههاى قابلتكيه دارد. & \\
\hline $9 V$ & $*$ & كفى صندلى يكيارجه و غيرصيقلى است. & \\
\hline va & 9 & براى دسترسى آسان به كليد برق، كليد در // تا س/1 متر از كف قرار كرفته است. & 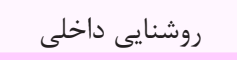 \\
\hline va & 9 & 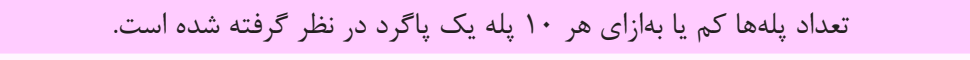 & راه يله \\
\hline$v \Delta$ & 9 & راهروها عرض كافى (حداقل · rا سانتيمتر) دارد. & 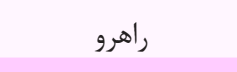 \\
\hline$V \Delta$ & 9 & درب فاقد آستانه و يا آستانهاى كمتر از • † ميليمتر دارد. & 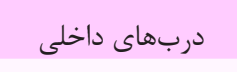 \\
\hline$\Lambda r$ & 1. & نرده در دو طرف راهِلهها قرار دارد و حداقل در يك طرف رمٍ نصب است. & \multirow{4}{*}{ مخصوص دستخيره } \\
\hline N & 1. & نردها يِوسته و بدون گَستتى و محكمم هستند. & \\
\hline$\vee \Delta$ & 9 & نرده در ارتفاع حدود له سانتيمتر از كف نصب شده است. & \\
\hline$v \Delta$ & 9 & داخل كابين آسانسور دستخيره محكم و مناسب در ارتفاع •^ تا •اسانتىمتر وجود دارد. & \\
\hline 94 & 11 & 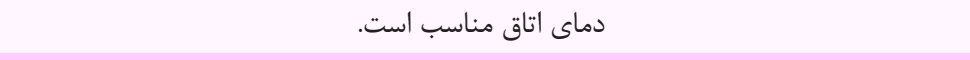 & \multirow{3}{*}{ اتاق } \\
\hline ᄉr & 1. & اتاق دستَيره يا وسايل كاملاً محكم و بى خطرى بهعنوان تكيه كاه دارد. & \\
\hline va & 9 & ارتفاع تخت براى افراد مسن مناسب است. & \\
\hline $1 \cdots$ & ir & خروجى هاى اضطرارى موجود است و بلوضوح مشخص شدهاند. & \multirow{4}{*}{ 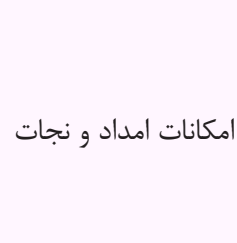 } \\
\hline $1 \cdots$ & ir & كيسول آتشنشانى موجود است. & \\
\hline ᄉr & 1. & برق اضطرارى در مسيرها و خروجىهاى اضطرارى موجود است. & \\
\hline$\Lambda$ & 1. & آشكارسازهاى دود در تمام نقاط داخلى بيمارستان وجود دارد. & \\
\hline
\end{tabular}

جدول r. فهرست كَيههاى اساسى در ابزار ارزيابى بيمارستانهاى دوستدار سالمند

\begin{tabular}{|c|c|c|c|}
\hline موافقت - مد & موافقت & \multirow[t]{2}{*}{ كويه } & ابعاد تناسب \\
\hline \multicolumn{2}{|c|}{ 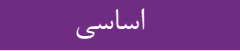 } & & \\
\hline$\Delta \wedge$ & $\checkmark$ & خارج از هر آسانسور، فضاى انتظار با صندلى مناسب موجود است. & آسانسور \\
\hline$\Delta \cdot$ & 4 & اتاق انتظار فضاى كافى براى كاربران صندلى خرخدار دارد & \multirow{2}{*}{ خدمات و امكانات } \\
\hline et & $\Delta$ & انواع وسايل كمكى براى حركت در مكان مناسب (ورودى، پاركينَ، طبقات و...) موجود است. & \\
\hline et & $\Delta$ & محل حوله، صابون و ديغر لوازم جانبى در ارتفاعى مناسب، محكم و در دسترس براى كاربران صندلى قرار & \multirow{2}{*}{ سرويس بهداشتى } \\
\hline Ft & $\Delta$ & درب حمام به سمت بيرون باز مىشود يا كشويى است. & \\
\hline et & $\Delta$ & ارتفاع صندلىها مناسب (حدود • ه-4\&) است. & 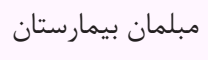 \\
\hline sV & $\wedge$ & علائم با خطوط ايتاليك، مواج يا نقطه هين نيست. & \multirow{3}{*}{ علائم راهنما } \\
\hline sV & $\wedge$ & تابلوها با نور مستقيم و غيرخيرهكننده روشن مىشوند. & \\
\hline$\Delta \cdot$ & द & علائم محل دسترسى به صندلى خرخدار يا موانع و خطرات در محل مناسب نصب است. & \\
\hline
\end{tabular}




\begin{tabular}{|c|c|c|c|}
\hline موافقت & موافقت & \multirow{2}{*}{ كويه } & \multirow{2}{*}{ ساختارى } \\
\hline \multicolumn{2}{|c|}{ 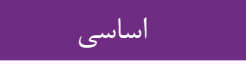 } & & \\
\hline$\Delta \cdot$ & \& & در محل تقاطع يا نقاطى با مسيرهاى متعدد علائم لازم نصب است. & \multirow{3}{*}{ علائم راهنما } \\
\hline et & $\Delta$ & نمادهاى تصويرى ساده و براى سالمندان بىسواد قابل فهمم است. & \\
\hline er & $\Delta$ & با استفاده از كدهاى رنكى تشخيص بخشها و مسيرها در بيمارستان ساده شده است. & \\
\hline qr & $\wedge$ & در محل اقامت بيماران، از :جراغهاى قابلتنظيم و دردسترس بيمار استفاده مىشود. & \multirow{4}{*}{ روشنايى داخلى } \\
\hline sr & $\wedge$ & براى جلوكيرى از خيركى، لامٍها حباب شفاف و يا قاب منعكس كنندة نور دارند. & \\
\hline$\Delta \wedge$ & v & روشنايى محيط داخلى بدون نقاط تاريك و روشن است. & \\
\hline$\Delta \cdot$ & द & روشنايى مناسب و غيرخيرهكننده درتمام نقاط بيمارستان وجود دارد. & \\
\hline et & $\Delta$ & دندانههاى روى رمب كمتر از · · ميلىمتر است. & رمب \\
\hline er & $\Delta$ & دستخيرؤ درب مدل اهرمى (كششى و فشارى) است و بهراحتى باز و بسته مىشود. & 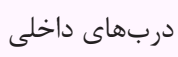 \\
\hline et & $\Delta$ & ينجرهها براى كنترل نور، يرده دارند. & \multirow{2}{*}{ 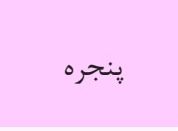 } \\
\hline et & $\Delta$ & ابزار كنترل ״رده در ارتفاع مناسب قرار دارد. & \\
\hline ఎ. & 4 & 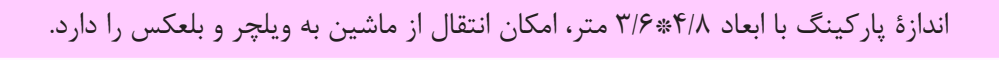 & 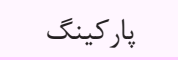 \\
\hline$\Delta \cdot$ & \& & نردهها تا حداقل • ب سانتىمتر يس از اتمام يله و تا رسيدن فرد به همسطح زمين ادامه مى يابد. & نرده مخصوص دستخيره \\
\hline
\end{tabular}

جدول F. فهرست تويههاى غيراساسى (ايدئال) در ابزار ارزيابى بيمارستانهاى دوستدار سالمند

\begin{tabular}{|c|c|c|c|}
\hline موافقت & موافقت & \multirow{2}{*}{ كويه } & \multirow{2}{*}{ ساختارى تناسب } \\
\hline \multicolumn{2}{|c|}{ ايدئال } & & \\
\hline זr & i & بهازاى هر ·ـ متر، در مسير حركت سالمندان صندلى وجود دارد. & \multirow[t]{2}{*}{ محيط يِيرامون } \\
\hline IV & r & ارتفاع ناهموارىهاى موجود در كف حداكثر · · ميلىمتر است. & \\
\hline$r \Delta$ & r & ورودىها بدون پيله است يا حداكثر اختلاف سطح فا ميلىمتر يا رمٍ دارد. & \multirow[t]{2}{*}{ ورودىها } \\
\hline$\wedge$ & 1 & عرض ورودى بيش از • 11 سانتىمتر (جهت عبور همزمان دو صندلى خرخدار) است. & \\
\hline$\wedge$ & 1 & عرض درب آسانسور در حالت باز بيش از ·9 سانتىمتر است. & \multirow{3}{*}{ آسانسور } \\
\hline$\wedge$ & 1 & كابين ابعاد مناسب (VY IVT سانتىمتر) براى ورود صندلى خرخدار به آسانسور دارد. & \\
\hline$\wedge$ & 1 & فاصلئ بين كابين و كف ساختمان در هر طبقه كمتر از ه/ النتىمتر است. & \\
\hline$\wedge$ & 1 & ارتفاع توالت فرنكى بين • •ه-4\& سانتىمتر است. & \multirow{3}{*}{ ورويس حماشتى } \\
\hline$\wedge$ & 1 & 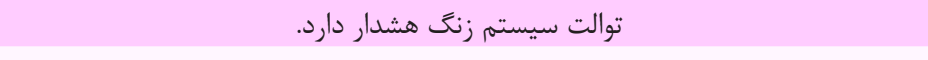 & \\
\hline iV & r & براى آبكشى، يك سردوش دستى و باصورت متحرك با شلنَ انعطاف يذير وجود دارد. & \\
\hline$\wedge$ & 1 & لبؤ يلهها با يك نوار رنكَى زرد يا رنَ مخالف ديخر مشخص شده است. & راه \\
\hline IV & r & شيب رمٍ كمتر از ^ درصد است. & رمب \\
\hline$\wedge$ & 1 & عرض تمام دربها بيشتر يا مساوى •9 سانتىمتر است. & مربها \\
\hline$\wedge$ & 1 & ياركينكى اختصاصى براى افراد معلول/ مسنتر در نزديكى ورودى اصلى وجود دارد. & \multirow{2}{*}{ 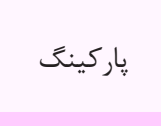 } \\
\hline$\wedge$ & 1 & هاركينَ رميى با شيبى كمتر از ^ درصد است. & \\
\hline$\wedge$ & 1 & همأ سطوح با شيبى بيش از ه درصد نرده دارند. & 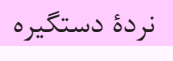 \\
\hline IV & r & فضاى كافى در دايرهاى به قطر ه/ امتر بهمنظور خرخش كامل ويلجر وجود دارد. & اتاق \\
\hline
\end{tabular}




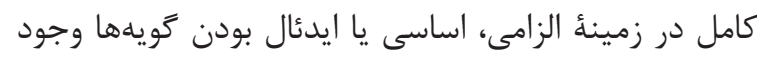

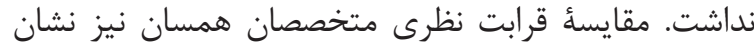

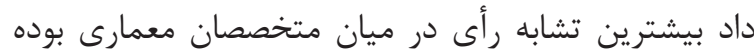

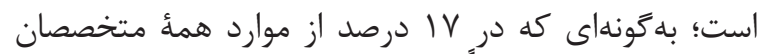

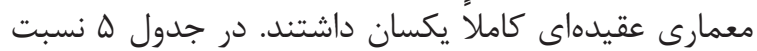

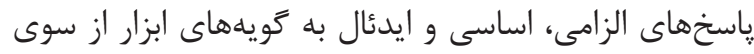

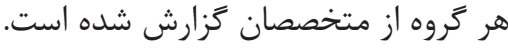

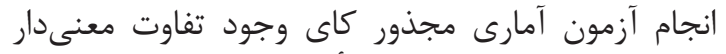

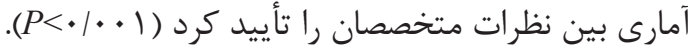

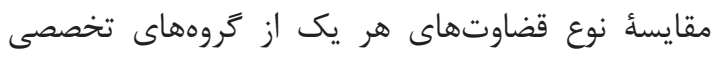

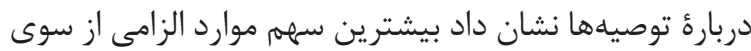

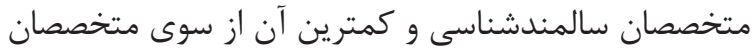

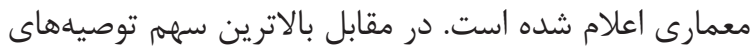

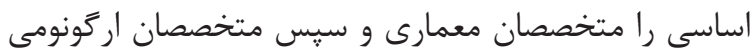

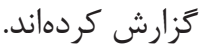

مقايسٔ نظرات متخصصان دربارة كَويههاى مختلف نئ نيز

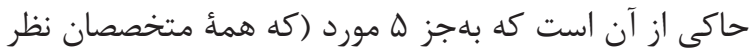

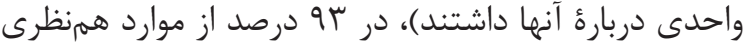

جدول ه. توزيع فراوانى نسبى قضاوت كروههاى تخصصى دربارة كويههاى ابزار تناسب ساختارى بيمارستان سالمنددوست

\begin{tabular}{|c|c|c|c|}
\hline متغير & \multicolumn{3}{|c|}{ نوع قضاوت دربارة اهميت هريك از كويهها (.)) } \\
\hline 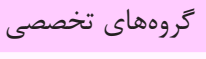 & الزامى & 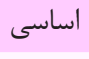 & ايدئال \\
\hline اركونوميست & rT/I & $9 / V r$ & $1 / 01$ \\
\hline سالمندشناس & $r / / Q$ & $9 / V I$ & $r / q V$ \\
\hline معمار & $r \cdot / T \Delta$ & $11 / \pi \mathrm{F}$ & $1 / V^{F}$ \\
\hline مجموع & $9 \Delta / \Delta 1$ & $r V / V V$ & GIVT \\
\hline
\end{tabular}

ضربان قلب سالمندان بسترىشده در واحد مراقبت ويزٔه قلبى

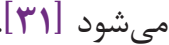

Nasiri

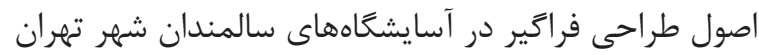

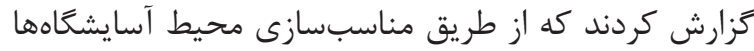

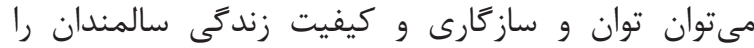

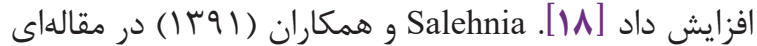

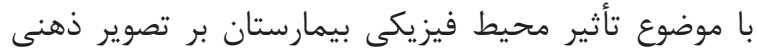

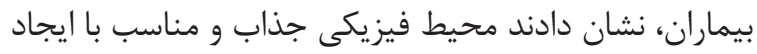

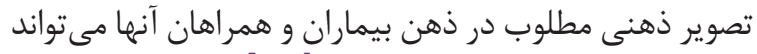

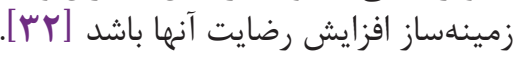

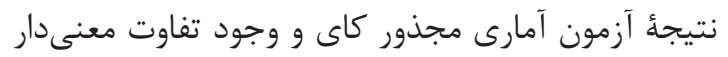

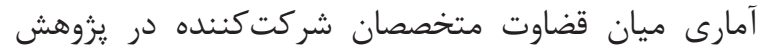
دئمأهاي

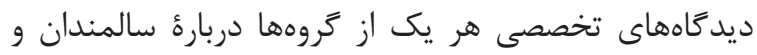

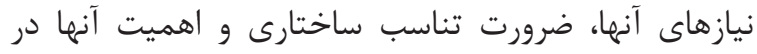

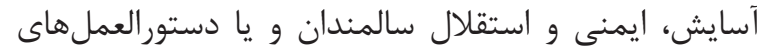

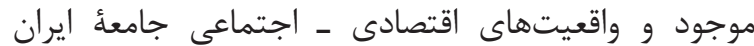

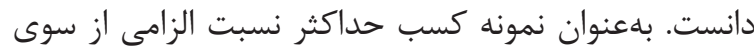

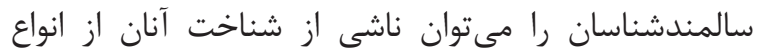

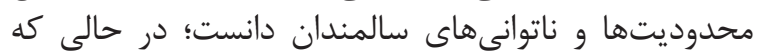

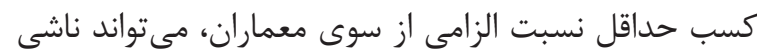

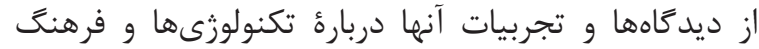

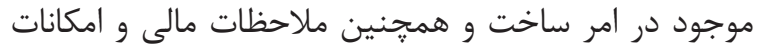
موجود براى ساخت بناها باشد.

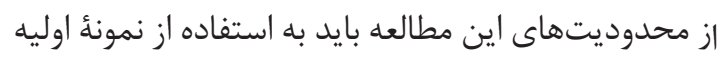
و ايرانى ابزار تناسب ساختارى در بيمارستانها و همجنين بـانين

\section{بحث و نتيجه كيرى}

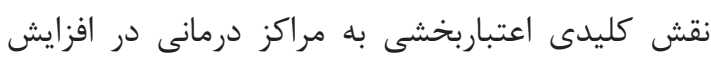

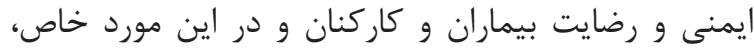

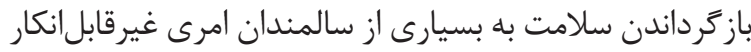

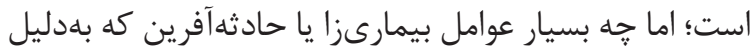

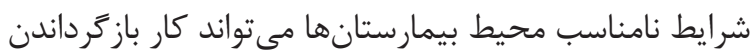

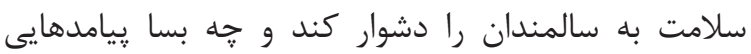

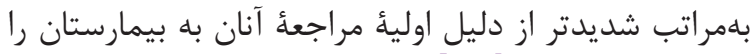

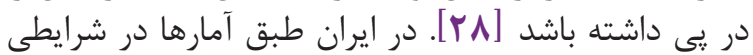

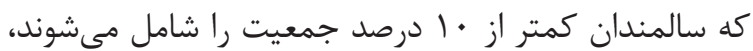

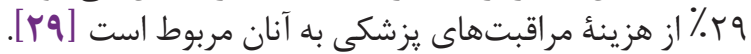
با توجه به مطالب يادشده و نظر به اثربخشى ملاحظات

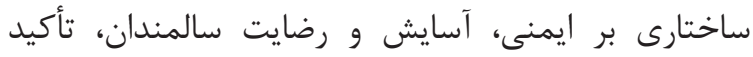

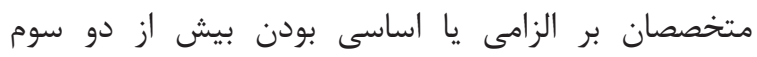

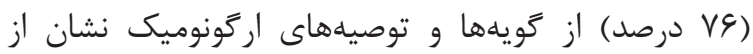

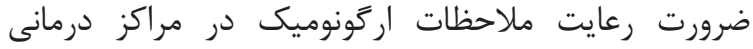

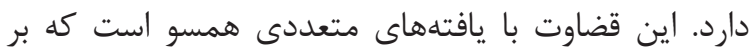

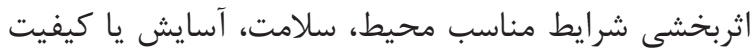

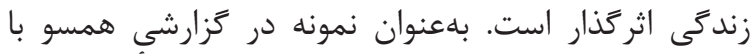

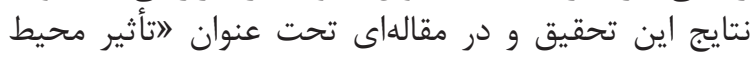

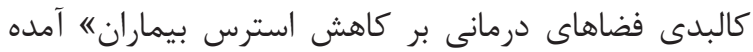

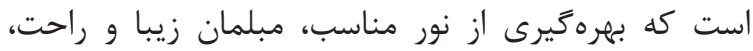

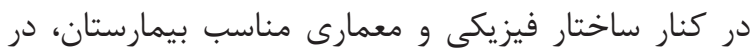

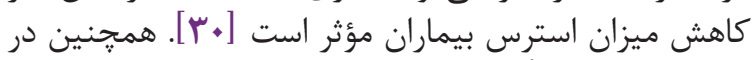

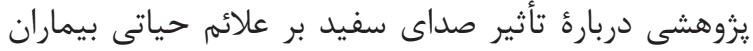

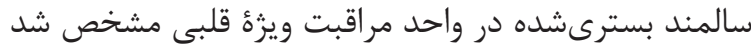
شنيدن صداى سفيد باعث كاهش اضطراب براب بيماران و كاهش 


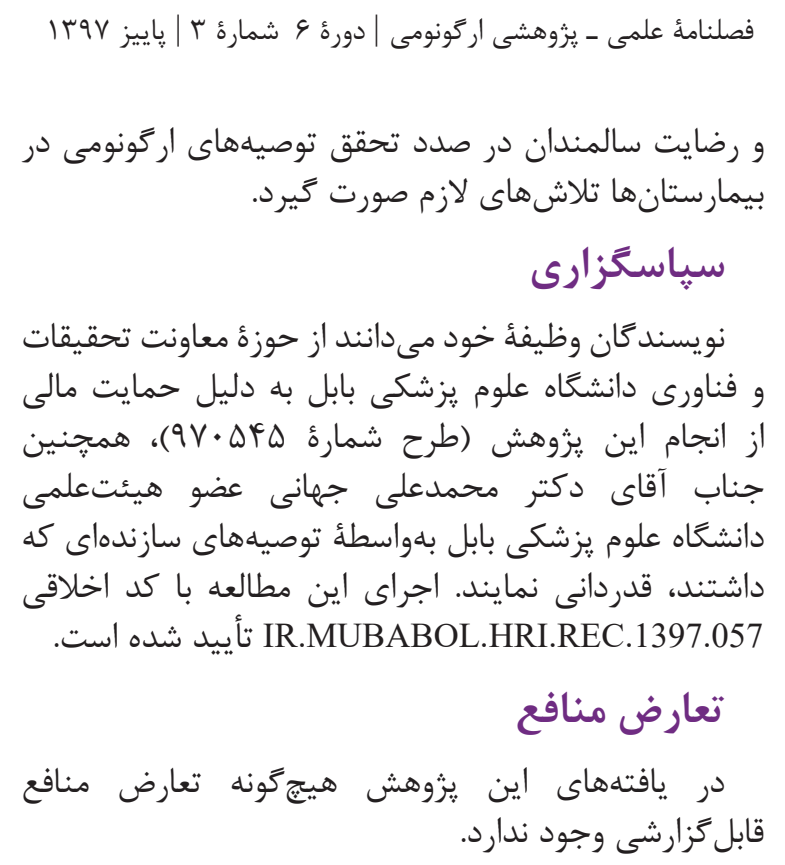

\section{References}

1. Riahi ME. A Comparative Study on the Status of Elderly In the Traditional and Modern Societies. Sālmand. 2008 Jan 1;3(3):10-21.

2. Belinda Parke, Kathleen Friesen. Kathleen Friesen RN BSN MA. Physical Design Components for an Elder Friendly Hospital. code plus. 2nd ed. British Columbia: Fraser Health. 2015.

3. Rezayi S, Manouchehri M. Comparison of mental disorders between home owner residents and nurse homes elders. Sālmand. 2008 Jan 1;3(1):16-25.

4. Reza AP, Mohammadkhani MM, Pooragha B. The Illness Patterns and Their Costs Among Hospitalized Elderly Covered by Medical Service Insurance Organization, in Damghan's Hospitals, in Year of 2005-2006. Sālmand. 2007 Jan 1;2(2):252-62.

5. Rasel M, Ardalan A. The future of ageing and its health care costs: A warning for health system. Sālmand. 2007 Jan 1;2(2):300-5.

6. Jazayeri A, Ariaei M, Minaei M. Nutritional status of elderly people. Journal of School of Public Health and Institute of Public Health Research. 2014 Oct 15;12(2):59-68.

7. Mirzaei M, Ghahfarokhi MS. Demography of elder population in Iran over the period 1956 To 2006. Sālmand. 2007 Jan 1;2(3):326-31.

8. Ahmadi A, Seyedin H, Fadaye-Vatan R. Towards age-friendly hospitals in developing countries: a case study in iran. Health promotion perspec-

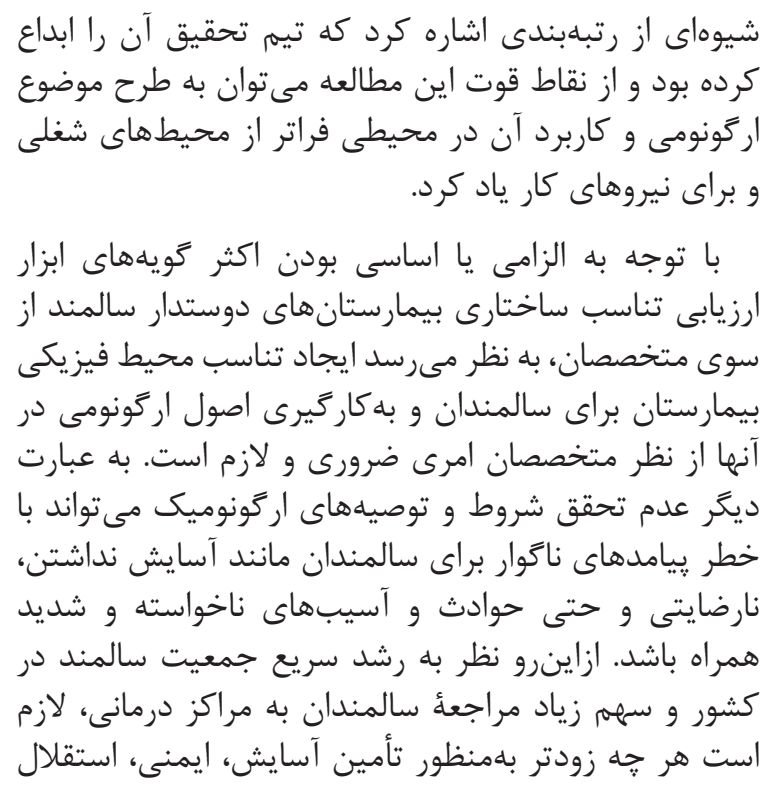

tives. 2015;5(1):42. https://doi.org/10.15171/ hpp.2015.006 PMID:26000245

9. Hatami H, Razavi SM, Eftekhar Arabili H, Majlesi F. The Textbook of Public Health, Third edition. Ariemand Pub. Tehran, 2013

10. Mirzaie M, Darabi S. Population Aging in Iran and Rising Health Care Costs. Iranian Journal of Ageing. 2017 Sep 15;12(2):156-69. https://doi. org/10.21859/sija-1202156

11. United Nations. Department of Economic and Social Affairs, population division. Trends in contraceptive use worldwide [Internet]. 2015. (ST/ESA/SER.A/390).

12. Javadian SR. Gerontological Social Work. Quarterly journal of social work. 2015 Sep 15;4(2):2732.

13. Arab M, Mousavi SM. The effect of accreditation system on the key performance indicators of hospitals affiliated to Tehran University of Medical Sciences: an interrupted time series analysis in 2012-2014. Journal of Hospital. 2017 Feb 15;16(1):17-26.

14. Salehian M, Riahi L, Biglarian A. The impact of accreditation on productivity indexes in Firoozgar hospital in Tehran. Journal of Health Administration (JHA). 2015;18(60).

15. Mosadeghrad AM, Akbari-sari A, Yousefinezhadi T. Evaluation of hospital accreditation standards. Razi Journal of Medical Sciences. 2017 Mar 15;23(153):43-54. 
آرام تيرگر و همكاران| ضرورت ملاحظات اركونوميك در اعتباربخشى ...

16. Hakkak M, Hozni SA, Shahsiah N, Akhlaghi T. Design of Hospital Accreditation Model: A Qualitative Study. Rāhburdhā-yi Mudīriyyat dar Nizāam-i Salāmat. 2017 Jan 1;2(3):201-14.

17. Wood P. Miami-Dade Age-Friendly Parks Toolkit. Health Foundation of South Florida.

18. Nasiri M, Foroughan M, Rashedi V, Makarem A, Jafari Mourjan B. Compliance to Universal Design Criteria in Nursing Homes of Tehran. Iranian Journal of Ageing. 2016 Jul 15;11(2):340-7. http://dx.crossref.org/10.21859/sija-1102340.

19. CÂMARA JJ, DE CASTRO ENGLER RI, DE OLIVEIRA FONSECA PR. Analysis and ergonomics of houses for elderly people. Periodicum biologorum. 2010 Mar 31;112(1):47-50.

20. Global Age-friendly Cities: A Guide. World Health Organization 2007.1-82.

21. Parke B. Physical Design Dimension of an Elder Friendly Hospital: An evidence-based practice review undertaken for the Vancouver Island Health Authority. University of Victoria Centre on Aging. 2007: 1-26.

22. Age-Friendly PHC Centers Toolkit. Geneva: World Health Organization; 2008.

23. Chiou ST, Chen LK. Towards age-friendly hospitals and health services. Archives of gerontology and geriatrics. 2009 Dec 1;49:S3-6. https://doi. org/10.1016/S0167-4943(09)70004-4

24. Huang AR, Larente N, Morais JA. Moving towards the age-friendly hospital: A paradigm shift for the hospital-based care of the elderly. Canadian geriatrics journal: CGJ. 2011 Dec;14(4):100._ https://doi.org/10.5770/cgj. v14i4.8 PMID:23251321

25. Eldemire-Shearer D. Age Friendly Primary Health Care Clinical Toolkit. Jamaica, Mona
Ageing and Wellness Centre, January. 2011.

26. Kim YS, Han SH, Hwang JH, Park JM, Lee J, Choi J, Moon Y, Kim HJ, Shin GJ, Lee JS, Choi YJ. Development of the Korean framework for senior-friendly hospitals: a Delphi study. BMC health services research. 2017 Dec;17(1):528. https://doi.org/10.1186/s12913-017-2480-0

27. Taheri F, Kavusi A, Faghihnia Torshozi Y, Farshad AA, Saremi M. Assessment of validity and reliability of Persian version of System Usability Scale (SUS) for traffic signs. Iran Occupational Health. 2017 Apr 15;14(1):12-22.

28. Tsai LY, Tsay SL, Hsieh RK, Yu S, Tsai JM, Chien HH, Liu SJ. Fall injuries and related factors of elderly patients at a medical center in Taiwan. International Journal of Gerontology. 2014 Dec 1;8(4):203-8. https://doi.org/10.1016/j. ijge.2013.10.007

29. Hajbaghery MA, Safa A, Aminolroayaee-Yamini E. Nurses' knowledge of ethical and legal issues in elderly care. Medical Ethics Journal. 2015;9(31):169-91.

30. Motalebi H, Vojdanzadeh L. Effect of Physical Environmental of Medical Space in Reducing Patients' Anxiety and Stress (Case Study: a Dental Office). Jfaup. 2015; 20(2): 35-4._

31. Farokhnezhad Afshar P, Mahmoudi A, Abdi A. The effect of white noise on the vital signs of elderly patients admitted to the cardiac care unit. joge. 2016; 1 (1):11-18.

32. Salehnia M, Kazemi M, Ahmadi Jazi S. Effect of physical environment of hospital on its image: Customer viewpoints. Hakim Journal. 2013;15(4):321-9. 